\title{
A review of the quality assurance processes for the Australasian Triage Scale (ATS) and implications for future practice
}

\author{
Alister Hodge, RN, BN, MN (Emerg) ${ }^{a, b, *}$ \\ Andrew Hugman, MBBS, FACEM, FCEM ${ }^{a}$ \\ Wayne Varndell, RN BSc (Hons) Nursing, Grad Dip (AP) ${ }^{\text {a,c }}$ \\ Kylie Howes, RN, BSc (Hons) Nursing, PGDip (Emerg) ${ }^{a}$ \\ a Prince of Wales Hospital, Emergency Department, Randwick, Australia \\ b Sydney Nursing School, The University of Sydney, Australia \\ c Faculty of Nursing, Health and Midwifery, University of Technology Sydney, Australia
}

Received 31 July 2012; received in revised form 12 December 2012; accepted 13 December 2012

\section{KEYWORDS \\ Triage; \\ Quality; \\ Australasian Triage \\ Scale (ATS); \\ Audit}

\begin{abstract}
Summary Triage is a critical component in the delivery of time-sensitive emergency care. Decision-making and the activity of the triage nurse affect patient access to care and allocation of emergency department (ED) resources. It is important to be able to evaluate decision-making at triage to ensure patient safety, and to identify opportunities for professional and service development. At present, there is no standard approach to retrospective examination of triage decisions using the Australasian Triage Scale. The aim of this literature review is to identify the quality control strategies used in triage and the factors that appear to influence triage decisions in relation to the Australasian Triage Scale.

Crown Copyright @ 2013 Published by Elsevier Ltd on behalf of College of Emergency Nursing Australasia Ltd. All rights reserved.
\end{abstract}

\footnotetext{
* Corresponding author at: The Prince of Wales Hospital, Emergency Department, Barker St., Randwick 2031, Australia. Tel.: +61293828423.

E-mail address: Alister.Hodge@sesiahs.health.nsw.gov.au (A. Hodge).
} 


\section{What is known}

- Triage is a critical component of ED practice, affecting access to care in relation to clinical urgency, patient disposition within the department and subsequent allocation of staff and equipment resources. Despite this, there is currently no standard approach to retrospective examination of triage decisions using the Australasian Triage Scale (ATS) to assess decision accuracy or to inform quality improvement exercises.

\section{What this paper adds}

- This paper details a review of existing triage quality frameworks and factors affecting triage decision making in relation to the Australasian Triage Scale, and suggests essential qualities that a future audit tool for retrospective triage decision analysis should contain.

\section{Introduction}

The emergency department (ED) is a time-sensitive and dynamic environment that manages high volumes of undifferentiated patients, many of which present simultaneously. To ensure patients receive time-critical intervention, all presenting patients are assessed and prioritized against their clinical urgency at triage by an emergency clinician, most usually a nurse using the Australasian Triage Scale. As an essential component of emergency nursing practice, it is important to be able to evaluate triage decision-making to maintain patient safety, and to identify opportunities for professional development at both the individual and service level. Presently in Australia, there is no standard or consensus approach to examining triage decisions using the Australasian Triage Scale (ATS).

\section{Background}

Multiple scales have been adopted in North America and Europe to standardize the assessment and prioritizion of patients presenting to the ED. ${ }^{1}$ In Australia and New Zealand, revisions to the National Triage Scale resulted in the development of the Australasian Triage Scale. ${ }^{2}$ The Australasian Triage Scale (ATS) consists of five tiers that link patient history, signs and symptoms to clinical urgency and the maximum time that patients should wait (see Table 1). ${ }^{3}$ A recent literature review completed by Australasian College for Emergency Medicine (ACEM) determined that the ATS is a valid measure of patient urgency, but is not validated as a measure of severity, complexity, staffing or workload. 4

Within Australia, triage is the first patient-healthcare professional contact in the $\mathrm{ED}^{5}$ and is usually completed by a trained emergency nurse. Triage is an essential function within ED where many patients present undiagnosed, unstable and without notice. ${ }^{6}$ Triage aims to ensure that patients are treated in order of clinical urgency, and that ED resources (staff, equipment and management area) are optimally deployed. Triage involves rapid assessment, interpretation of the clinical history and physiological assessment, allocation of an urgency code and allocation to the appropriate area of ED. ${ }^{6}$ The triage episode is generally expected to take no more than 2-5 min, balancing speed and thoroughness to ensure the triage assessment itself does not impede access to necessary clinical intervention. ${ }^{5}$ Processes undertaken as part of triage such as documentation should be brief and concise in conveying the clinical picture of the patient's level of urgency; containing the minimum amount of information required (see Table 2 ). ${ }^{5}$

Most Australian hospitals currently use an electronic record system to document patient assessments including triage information, such as: patient's name, age, time of triage interview, allergies, level of pain and vital signs. ${ }^{7}$ These electronic record systems may offer the potential to quickly evaluate triage decision-making accuracy and consistency, compared to paper-based record systems.

\section{Aim}

This paper aims to identify the quality control strategies used in triage and the factors that appear to influence triage decisions in relation to the Australasian Triage Scale.

\section{Search strategy}

Medline and Nursing@Ovid were searched for the terms TI triage and aust*, or, TI Australasian Triage Scale, or, TI triage and quality control.

Table 1 ATS categories, descriptions and maximum waiting times, performance thresholds ${ }^{29}$ and admission targets. ${ }^{30}$

\begin{tabular}{lllll}
\hline Cat & Description & $\begin{array}{l}\text { Treatment acuity } \\
\text { (max wait time) }\end{array}$ & $\begin{array}{l}\text { Performance } \\
\text { thresholds (\%) }\end{array}$ & $\begin{array}{l}\text { Hospital admission } \\
\text { rates targets }(\%)\end{array}$ \\
\hline 1 & Immediately life-threatening & Immediate & 100 & $75-90$ \\
2 & Imminently life-threatening & $10 \mathrm{~min}$ & 80 & $60-70$ \\
3 & Potentially life-threatening & $30 \mathrm{~min}$ & 75 & $50-60$ \\
4 & Potentially serious & $60 \mathrm{~min}$ & 70 & $20-30$ \\
5 & Less urgent & $120 \mathrm{~min}$ & 70 & $5-10$ \\
\hline
\end{tabular}


Table 2 Triage documentation standards. ${ }^{5}$

Date and time

Name of person completing triage

Chief presenting problem(s)

Limited relevant history

Relevant assessment findings

Initial triage category

Re-triage category with time and reason (If clinical condition

alters)

Assessment or treatment area allocated

Any diagnostic, first aid or treatment measures initiated

\section{Screening and data extraction}

The search covered the period from 1996 to 2012. No data restrictions were initially applied. A total of 574 titles and abstracts were reviewed by abstract and title. From the 574 articles, 34 studies were retrieved, identified and examined (see Fig. 1). The author read and assessed all articles. Articles were evaluated using Critical Appraisal Skills Program $(\text { CASP })^{8}$ making sense of evidence tools. Inclusion criteria included: quality-control processes surrounding triage assessment and documentation, reliability and validity testing of the ATS, or, factors affecting triage decision making. Commentaries, descriptive or opinion pieces were excluded from the review.

\section{Databases accessed}

The following databases were researched: Medline and OVID. The review was supplemented by searching the reference lists of identified articles, and a manual search of the relevant gray literature.

\section{Results}

Thirty-four studies were found to be relevant. Only one article was identified addressing triage quality processes, ${ }^{19}$ compared to studies examining factors effecting triage nurse decision-making/activity. ${ }^{2,6,8,10,21,24}$ Approximately a quarter of studies identified examined the reliability and validity of triage nurse decision-making using the ATS. ${ }^{3,16,19,20,22-25,27}$

\section{Triage quality processes}

There are three possible outcomes upon evaluation of a triage decision; expected, over-triage and under-triage. An expected triage decision is where the history and physiological assessment are considered concordant with the triage code allocated. Over-triage is the allocation of a category of higher urgency than appears necessary. Conversely, under-triage is the allocation of a category of less urgency than necessary. ${ }^{9}$ Discussion of audit tools to evaluate

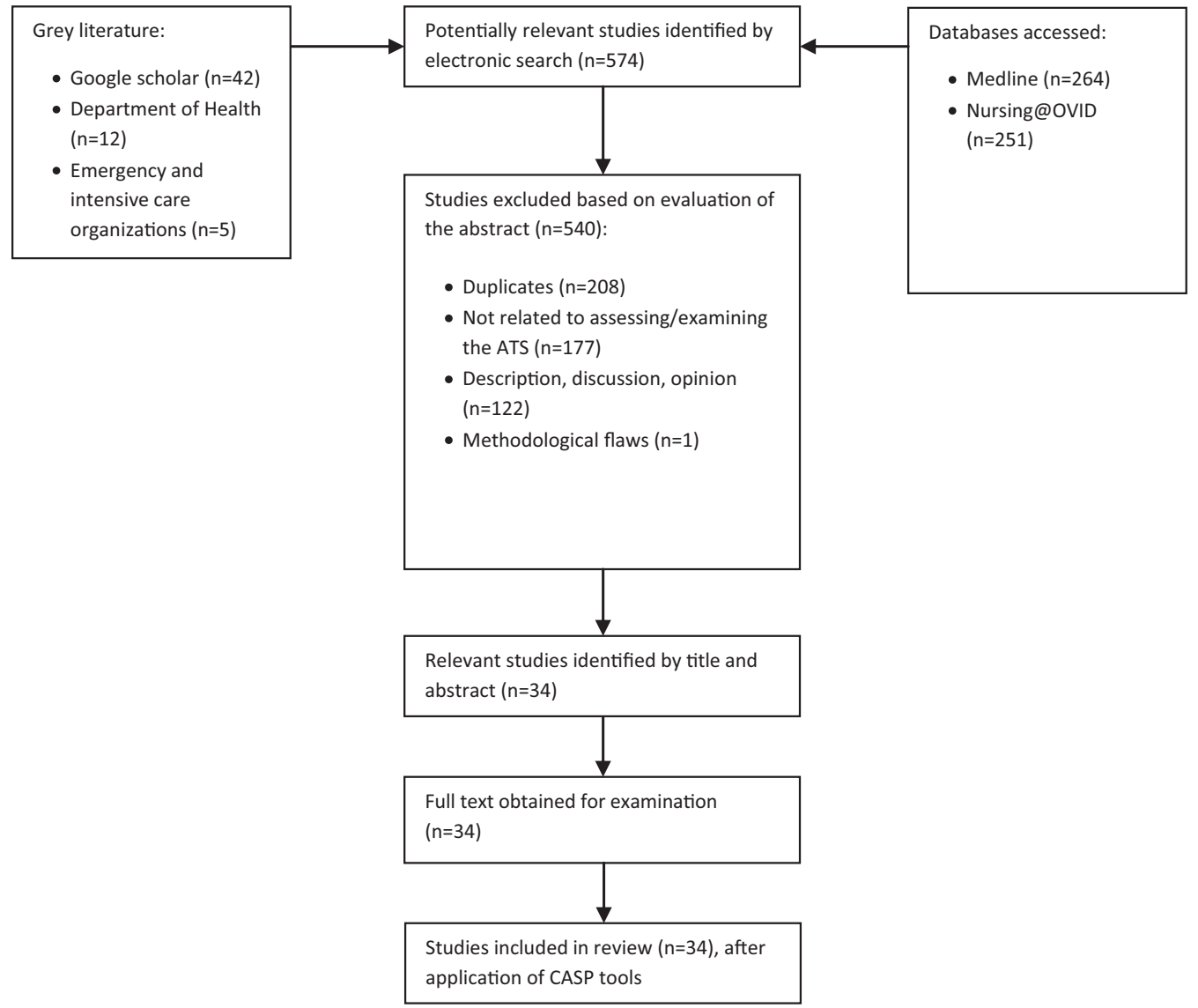

Fig. 1 Search results. 
documentation recorded during the triage assessment was infrequent within the literature.

The only reported quality audit tool specific to the ATS was developed in Victoria as part of the 'Consistency of Triage in Victoria's Emergency Departments Project', completed in 2001. ${ }^{10}$ This project recommended the evaluation of four key performance areas including:

- Triage nurse education: percentage of triage nurses who have completed specific educational preparation for the triage role.

- Waiting times: percentage of patients in each category receiving treatment within designated times.

- Admission rates: the rate of hospital admissions associated with each category.

- Retrospective chart audit: audit of triage documentation.

The Victorian audit tool was developed to reflect physiological parameters and risk factors found in the TERB, ${ }^{11}$ and is presented in a primary survey approach in relation to the ATS categories. The information gained using the audit tool leads the auditor to a decision regarding adequacy of documentation, and appropriateness of the triage category for the patient's physiological status.

The tool has a number of strengths. The primary survey approach taken by the tool aids the identification of relevant physiological and historical indicators to justify triage code allocation. Arguably, however, there are gaps in the data provided by the tool. It does not provide an indication of other relevant triage variables such as the time taken to complete the triage, and there is limited functionality within the tool to articulate the source of the incorrect triage category allocation.

\section{Factors affecting triage decisions}

Factors that have been cited in the literature to affect triage decision-making include ED activity level, ${ }^{12}$ medical and nursing skill mix, ${ }^{13}$ lack of triage education, ${ }^{6}$ and the type of ED presentation, e.g. mental health and pregnancy. ${ }^{14}$ In an examination of quiet versus busy departments, Creaton et al. ${ }^{12}$ showed that triage decision accuracy could vary as much as $25 \%$ (range $6.6-25.6 \%$ ). ${ }^{28}$ Interestingly Considine et al. ${ }^{15}$ demonstrated that increasing frequency of triage shifts positively correlated to higher over-triage rates $(p=0.041)$, and that Clinical Nurse Specialists and Nurse Unit Managers were less likely to over-triage $(p=0.021)$. Doherty ${ }^{16}$ found that nurses' triage decisions demonstrated higher uniformity than Emergency Physicians or Trainees. A study of NSW triage nurses found that feeling ill prepared for triage influenced clinical reasoning abilities and the speed of decision making. ${ }^{17}$ Following the introduction of the 'Australasian Association of Emergency Nurses (AAEN) recommendations for triage education' in 2002, nurses who have since been educated in triage felt considerably more prepared for the role than their senior colleagues. ${ }^{18}$

Another major contributor to decision variability and inaccuracy is likely to be the scarcity of objective physiological discriminators attached to the ATS in ACEM Guideline 24 'Guidelines of the implementation of the Australasian
Triage Scale in Emergency Departments'. ${ }^{5}$ Although broad descriptors for degree of compromise are linked to certain categories (e.g. ATS 2 'severe respiratory distress'), objective signs and symptoms that are accepted to define such terms as 'severe' are not stated for the adult patient. ${ }^{10}$

\section{Reliability and validity testing using the ATS}

From the literature review no studies were identified that examined the validity of the ATS, and have instead focused upon reliability, i.e. consistency. Various approaches have been taken to assess triage decision consistency when categorizing patients using the ATS, 1,10,15,16,19-21 however, to date, few studies have intentionally sought to measure 'decision accuracy'. Decision accuracy relates to the intensity of total agreement between test scores and model responses, whereas 'decision consistency' refers to the distance between test scores and model responses. ${ }^{22}$

In the eight papers that studied triage quality assurance, decision accuracy was shown to vary widely from $32.2 \%$ to 83.8\% (see Table 3). ${ }^{10,12,21}$ Measuring triage decision consistency with the ATS has largely focused on measures of inter-rater reliability using various permutations of Cohen's kappa co-efficient (see Table 4). ${ }^{23}$ This inconsistent use of the kappa statistic limits the ability to compare studies, and in some instances may not be appropriate for the type of data being examined. ${ }^{24}$

\section{'Triage-weighted kappa'}

An alternative weighted-kappa, denoted as the 'triageweighted kappa' has recently been proposed for measuring triage inter-rater reliability by van der Wulp and van Stel. ${ }^{25}$ This alternative kappa algorithm is based upon the concern that linear and quadratically weighted kappas are symmetrically weighted, therefore their values do not reflect the clinical significance of under or over-triage. For example, a disagreement of two levels under symmetrically weighted kappa schemes still counts as $75 \%$. Whereas, in the clinical practice of triage, under or over triaging a patient by two levels could either have serious ramifications for patient safety (under-triaging), or waste of ED resources (overtriaging). The triage-weighted kappa weighting scheme has been adjusted to reflect this. On comparing five ATS inter-rater assessments from two studies, ${ }^{15,26}$ the newly calculated triage-weighted kappa appeared much lower than their respective quadratically weighted kappa with a mean difference of 0.186 (range $0.15-0.22$ ) (see Table 5).

However, whilst there may be merit in considering the recently proposed triage-weighted kappa for future studies, literature attesting to triage decision consistency was published prior to the development of the triageweighted kappa. During the period when these studies were published calculation of weighted-kappa values was recommended. ${ }^{24,27}$

Results from included studies varied. Interestingly two studies $^{9,20}$ used a non-weighted kappa $(\kappa)$, instead of a weighted kappa $\left(\kappa_{w}\right)$ when assessing ordinal data. Only two studies used comparable weighted kappa measures 
Table 3 Summary of studies testing the reliability and validity of nurse decision making using the ATS.

\begin{tabular}{|c|c|c|c|c|c|}
\hline Study & Year & Method & $\begin{array}{l}\text { Population and No. of scenarios } \\
\text { and assessments }\end{array}$ & Assessment of ATS reliability & $\begin{array}{l}\text { Assessment of } \\
\text { ATS validity }\end{array}$ \\
\hline Gerdzt et al. ${ }^{1}$ & 2008 & $\begin{array}{l}\text { Paper-based } \\
\text { scenarios }\end{array}$ & $\begin{array}{l}237 \text { paper-base mixed } \\
\text { population triage scenarios, } \\
\text { non-random selection of ED } \\
\text { nurses }(n=50) .42 \text { completed } \\
\text { questionnaires returned } \\
\text { totaling } 9954 \text { assessments. }\end{array}$ & $\begin{array}{l}\text { Overall inter-rater score } \kappa_{w}=0.412(\mathrm{Cl} 95 \% \\
0.410-0.415) \text {. ATS } 1 \kappa_{w}=0.609 ; \text { ATS } 2 \kappa_{w}=0.403 ; \text { ATS } 3 \\
\kappa_{w}=0.314 ; \text { ATS } 4 \kappa_{w}=0.420 \text { and ATS } 5 \kappa_{w}=0.545 . \\
\text { Scenario type: mental health }\left(m^{a}=40\right) \kappa_{w}=0.243(\mathrm{Cl} \\
0.237-0.249) \text {; pediatric }(m=41) \kappa_{w}=0.385(\mathrm{Cl} \\
0.379-0.391) ; \text { pain }(m=72) \kappa_{w}=0.409(\mathrm{Cl} 0.404-0.414) \text {; } \\
\text { pregnancy }(m=21) \kappa_{w}=0.319(\mathrm{Cl} 0.310-0.328) \text { and } \\
\text { triage basic }(m=63) \kappa_{w}=0.612(\mathrm{Cl} 0.508-0.516) .\end{array}$ & Not tested \\
\hline Creaton et al. ${ }^{12}$ & 2008 & $\begin{array}{l}\text { Video Simulated } \\
\text { scenarios }\end{array}$ & $\begin{array}{l}90 \text { nurses rated } 6 \text { videos of } 3 \\
\text { simulated adult mental health } \\
\text { scenarios of inter-mediate risk } \\
\text { (ATS 3), occurring in either } \\
\text { busy or quite environments. }\end{array}$ & $\begin{array}{l}\text { Overall, inter-rater concordance ranged from } 53.3 \% \text { to } \\
65.6 \% \text { for correct category allocation. Dysthymia and } \\
\text { busy environment } 14.4 \%(8.2-23.8 \%) \text { versus quiet } \\
\text { environment } 40.0 \%(30.0-50.9 \%) \text {; personality disorder } \\
\text { and busy environment } 53.3 \%(42.5-63.8 \%) \text { versus quiet } \\
\text { environment } 46.7 \%(36.2-57.5 \%) \text { and psychosis and busy } \\
\text { environment } 53.3 \%(42.5-63.8 \%) \text { versus quiet } \\
\text { environment } 64.4 \%(30.0-50.9 \%) \text {. }\end{array}$ & Not tested \\
\hline Gerdtz and Bucknall ${ }^{19}$ & 2007 & $\begin{array}{l}\text { Paper-based } \\
\text { scenarios }\end{array}$ & $\begin{array}{l}66 \text { nurses completed } 12 \\
\text { paper-based scenarios, totaling } \\
744 \text { assessments. }\end{array}$ & $\begin{array}{l}\text { Agreement among raters varied from } \kappa_{w}=0.18-0.64 \text {, } \\
\text { overall agreement } \kappa_{w}=0.38(\mathrm{Cl} 0.38-0.39) \text {. Inter-rater } \\
\text { agreement per category: ATS } 1 \kappa_{w}=0.64(\mathrm{Cl} 0.63-0.65) \text {; } \\
\text { ATS } 2 \kappa_{w}=0.36(\mathrm{Cl} 0.34-0.37) ; \text { ATS } 3 \kappa_{w}=0.21(\mathrm{Cl} \\
0.19-0.22) ; \text { ATS } 4 \kappa_{w}=0.50(\mathrm{Cl} 0.48-0.51) \text { and ATS } 5 \\
\kappa_{w}=0.18(\mathrm{Cl} 0.16-0.19)\end{array}$ & Not tested \\
\hline Considine et al. ${ }^{9}$ & 2004 & $\begin{array}{l}\text { Paper and } \\
\text { computer-based } \\
\text { scenarios }\end{array}$ & $\begin{array}{l}167 \text { nurses completed } 2349 \\
\text { adult scenarios. }\end{array}$ & $\begin{array}{l}\text { Percentage of agreement using computer-based adult } \\
\text { triage scenarios was } 64.5 \%\left(\kappa=0.54, \tau_{b}=0.74 ;\right. \\
p<0.0001) \text {; over-triage } 20 \% \text { and under-triage } 15.5 \% \text {. } \\
\text { Percentage of agreement using paper-based adult triage } \\
\text { scenarios was } 56.6 \%\left(\kappa=0.43, \tau_{b}=0.76 ; p<0.0001\right) \\
\text { over-triage was } 25.8 \% \text {, under-triage } 17.6 \% \text {. }\end{array}$ & Not tested \\
\hline LeVasseur et al. ${ }^{10}$ & 2001 & $\begin{array}{l}\text { Paper and } \\
\text { computer-based } \\
\text { scenarios }\end{array}$ & $\begin{array}{l}26 \text { EDs, } 161 \text { raters enrolled by } \\
\text { random stratification, } 7 \\
\text { paper-based scenarios, } 7 \\
\text { computer-based scenarios, } \\
\text { totaling } 2254 \text { assessments. }\end{array}$ & $\begin{array}{l}\text { Correct adult computer-based scenarios (mean) } 64.63 \% \\
\text { (SD 16.39\%) compared to correct paper-based scenarios } \\
\text { (mean) } 56.46 \% \text { (SD16.75\%), } p<0.001 \text {. }\end{array}$ & Not tested \\
\hline Considine et al. ${ }^{30}$ & 2000 & $\begin{array}{l}\text { Paper-based } \\
\text { scenarios }\end{array}$ & $\begin{array}{l}2 \text { EDs, } 31 \text { triage nurses } \\
\text { completed } 10 \text { paper-based } \\
\text { scenarios totaling } 310 \\
\text { assessments. }\end{array}$ & $\begin{array}{l}\text { Overall respondent percentage for expected triage } \\
\text { category ranged from } 32.2 \text { to } 83.8 \% \text {. Higher frequency of } \\
\text { triage shifts positive correlated to a higher over-triage } \\
\text { rate }(p=0.041) \text {. Clinical Nurse Specialists and unit } \\
\text { Managers were less likely to over-triage }(p=0.021) \text {. }\end{array}$ & Not tested \\
\hline
\end{tabular}




\begin{tabular}{|c|c|c|c|c|c|}
\hline Study & Year & Method & $\begin{array}{l}\text { Population and No. of scenarios } \\
\text { and assessments }\end{array}$ & Assessment of ATS reliability & $\begin{array}{l}\text { Assessment of } \\
\text { ATS validity }\end{array}$ \\
\hline Dilley and Standen ${ }^{20}$ & 1998 & $\begin{array}{l}\text { Paper-based } \\
\text { scenarios }\end{array}$ & $\begin{array}{l}14 \text { EDs, } 188 \text { triage nurses } \\
\text { assessed } 20 \text { paper-based } \\
\text { scenarios totaling } 3760 \\
\text { assessments. }\end{array}$ & Overall inter-rater agreement $\kappa=0.2537$. & Not tested \\
\hline Doherty ${ }^{16}$ & 1996 & $\begin{array}{l}\text { Paper-based } \\
\text { scenarios }\end{array}$ & $\begin{array}{l}4 \text { EDs, } 8 \text { triage nurses, } 8 \text { FACEM } \\
\text { and } 8 \text { registrars assessed } 12 \\
\text { paper-based scenarios totaling } \\
288 \text { assessments. }\end{array}$ & $\begin{array}{l}\text { Of the } 12 \text { scenarios assessed, } 83.3 \% \text { received triage } \\
\text { varying by } 3 \text { or more categories. No scenario was triaged } \\
\text { the same by all respondents. A mean variance in triage } \\
\text { score per hospital was calculated at } 0.45 \text { (range } \\
2.63-3.08 \text { ). } 6 \text { nurses agreed on the triage score for } 9 \\
\text { scenarios, } 5 \text { nurses agreed on the triage score for every } \\
\text { scenario. Data Table } 1 \text { missing showing nurses compared } \\
\text { with physicians triage assessments, paper states, "[The } \\
\text { nurses' scores were]... far more uniform than FACEMs } \\
\text { and registrars"' }\end{array}$ & Not present \\
\hline Jelinek et al. ${ }^{21}$ & 1996 & $\begin{array}{l}\text { Paper-based } \\
\text { scenarios }\end{array}$ & $\begin{array}{l}8 \text { EDs, } 115 \text { triage nurses, } 100 \\
\text { paper-based scenarios totaling } \\
11,500 \text { assessments. }\end{array}$ & $\begin{array}{l}115 \text { respondents were within } 1 \text { category of the model } \\
\text { response. Concurrence, more than } 50 \% \text { of the } \\
\text { respondents agreed with the profiles model response. }\end{array}$ & Not present \\
\hline
\end{tabular}

a $m=$ number of triage scenarios.

b FACEM, Fellow of Australasian College for Emergency Medicine. 
Table 4 Kappa Interpretation. ${ }^{31}$

\begin{tabular}{clcl}
\hline Value of $\kappa$ & $\begin{array}{l}\text { Strength of } \\
\text { agreement }\end{array}$ & Value of $\kappa$ & $\begin{array}{l}\text { Interpretation of } \\
\text { clinical significance }\end{array}$ \\
\hline$<0.2$ & Poor & $<0.40$ & Poor \\
$0.21-0.40$ & Fair & $0.40-0.59$ & Fair \\
$0.41-0.60$ & Moderate & $0.60-0.74$ & Good \\
$0.61-0.80$ & Good & $0.75-1.00$ & Excellent \\
$0.81-1.00$ & Very good & & \\
\hline
\end{tabular}

Table 5 ATS inter-rater agreement measured with quadratically weighted kappa versus triage-weight kappa.

\begin{tabular}{|c|c|c|c|c|c|c|}
\hline Study & Groups & $N$ ratings & $\begin{array}{l}\text { Quadratic } \\
\text { weighted }(95 \% \mathrm{Cl})\end{array}$ & $\begin{array}{l}\text { Triage-weighted } \\
(95 \% \mathrm{Cl})\end{array}$ & Over-triage (\%) & Under-triage (\%) \\
\hline Considine et al. ${ }^{15}$ & Nurses vs. experts & 310 & $0.86(0.84-0.89)$ & $0.67(0.61-0.72)$ & 20.97 & 20.97 \\
\hline \multirow[t]{4}{*}{ Considine et al. ${ }^{9}$} & Nurses vs. experts & 1176 & $0.82(0.80-0.84)$ & $0.64(0.60-0.67)$ & 19.98 & 15.47 \\
\hline & Nurses vs. experts & 1133 & $0.89(0.87-0.90)$ & $0.74(0.71-0.77)$ & 13.95 & 18.18 \\
\hline & Nurses vs. experts & 1173 & $0.81(0.79-0.82)$ & $0.62(0.59-0.65)$ & 25.83 & 17.56 \\
\hline & Nurses vs. experts & 1132 & $0.80(0.78-0.82)$ & $0.58(0.55-0.61)$ & 22.88 & 22.88 \\
\hline
\end{tabular}

of inter-rater reliability, ${ }^{1,19}$ showing overall triage decision consistency ranging from fair to moderate $\left(\kappa_{w}=0.38-0.56\right)$. Examining inter-rater reliability between ATS categories, categories 1 and 4 demonstrated higher inter-rater reliability than any other single category $\left(\kappa_{w}=0.609-0.64\right)$. Inter-rater reliability by scenario type further revealed varying levels of agreement, from fair (mental health, $\kappa_{w}=0.243$ ) to moderate (pain, $\left.\kappa_{w}=0.41\right){ }^{1}$

\section{Discussion}

The review identified that inter-rater reliability using a quadratically weighted kappa does not reflect the risk and severity of an under/over ATS triage category allocation. There was also no standard audit method to enable critique of triage decisions. A further interesting finding exists in the decline of nurses participating in annual auditing who were triage educated in accordance with the AAEN guidelines. ${ }^{18}$ The process of monitoring triage decision-making using a defined and standardized criteria in order monitor and sustain quality improvement is therefore likely to be very important.

\section{Triage audit methods}

The paucity of literature covering triage performance assessment demonstrates the difficulties of triage quality assurance. An ideal triage audit tool should have a number of properties: it must be able to be used by a variety of ED staff; secure; be adaptable to a variety of hospital information systems used to record triage; be able to automatically de-identify the triage record to limit auditor bias, and on completion provide a record of individual triage nurse performance; and be able to highlight common areas for improvement and education at the departmental level (Table 6).

\section{Retrospective vs. prospective vs. scenario-based process}

In an ideal environment, the best method to evaluate a triage decision would be to directly observe the whole interaction. This could either be done by having two 'expert triage nurses' observe the initial triage, or alternatively, video record the triage interview and assess at a later date. Whilst this would decrease reliance upon triagedocumented text to convey an accurate clinical picture of the patient and a subsequent determination of triage decision accuracy, it would be an impractical drain on time and resource allocation for most EDs. Prospective auditing could also possibly introduce a Hawthorne effect ${ }^{28}$ in which subjects would tailor their behavior due to being studied and preclude any blinding measures to decrease auditor bias.

The alternative to prospectively evaluating triage decisions is to retrospectively assess triage documentation. This approach is the most practical choice to assess a representative sample of triages, and therefore the most likely method to be sustainable in the long term. It allows blinding of auditors to the triage nurse name and original category allocation to avoid introducing an unacceptable level of bias, and provides an indication of what information the triage nurse viewed as key for a given type of presentation. However, limitations are noted as it only enables assessment of whether or not the documented information reflects an appropriate allocation of category and disposition. Furthermore, it cannot indicate whether the recorded assessment was an accurate reflection of the patient's actual clinical condition. Scenario-based models, whilst designed diligently, can never replace the actual assessment of genuine patient presentations and have only been used in lieu of the lack of a more reliable assessment method. 
Table 6 Suggested components of an ideal triage audit tool.

Easy to use: minimal training required.

Good internal validity: auditors are exposed to all aspects of clinical judgment, such as direct observation of the patient at presentation including visual and non-verbal cues, as well as the documented record of the triage assessment.

Standardized with good external validity: the tool would be able to be used in different ED using different Health

Information Systems and interfaces with commonly used spreadsheet/database software (e.g. Microsoft Excel, Access).

Sustainable: The audit process is not too time consuming and does not rely on impractical large numbers of staff or

resources.

Blinding: Auditors are blinded to patient and triage nurse identification, however the ability to re-identify staff member in

the event of clinical performance concerns should be included.

Capacity to direct education efforts: the ability to improve triage accuracy at the departmental and individual level.

\section{Paper-based vs. electronic format}

To date, most triage audit processes have been paperbased where triage case notes are retrospectively assessed. Analysis of such data provides useful information regarding department and individual triage accuracy, which can be used to target performance development activities. However, analysis presents a sizeable time commitment, particularly during the data extraction phase post-audit completion.

To combat these issues, future efforts to create a consistent framework to retrospectively audit ATS triage encounters must consider utilizing an electronic format. This would allow blinding of triage nurse and category and support automatic report generation post-audit completion.

For many years, Australian EDs have used a variety of Hospital Information Systems for patient tracking and triage data recording, and the increasing sophistication of such software potentially allows greater integration with quality control of ED processes. This may allow a robust quality assurance process that can be performed with a minimum of time and resources, thereby enhancing the likely sustainability of the QA process.

\section{Conclusion}

Triage is a critical component of ED practice affecting access to care and departmental resource allocation. For triage decisions to be accurate and consistent several factors are important: the presence of consistent education regarding triage scale utilization, clear guidelines that are easily understood and interpreted, and a quality framework to audit outcomes. Variability in decision accuracy and consistency at triage translates into irrational variation of patient waiting times with similar clinical urgency. Accurate and timely decisions are needed to maintain patient safety and ensure that triage itself does not become a barrier to clinical treatment.

Studies of triage decision consistency found only fair to moderate inter-rater reliability, while decision accuracy has been shown to vary widely. Although ACEM have found that the ATS is valid for determining the urgency in which a patient needs to be seen, a standard quality process does not exist in Australia to examine documented triage decisions. This is an important omission for ED quality improvement processes, as a standardized approach to retrospective appraisal of completed ATS triage decisions would both provide a measure of current performance and direct educational developments. Retrospective analysis of triage documentation is likely to be the most practical audit framework to allow assessment of triage decision accuracy. Future audit tools should consider utilizing an electronic format to support blinding of relevant data and automatic report generation to decrease time demands upon the clinician and support sustainability of the quality exercise.

\section{Authors' contributions}

Alister Hodge involved in the conception and design of paper, acquisition of literature, analysis of literature, writing, drafting and final approval of draft. Andrew Hugman involved in the contribution to the design of paper, text writing, drafting of paper and approval of draft. Wayne Varndell involved in the contribution to design of paper, analysis of literature, contribution to text writing, drafting of paper and approval of draft. Kylie Howes involved in the contribution to design of paper, text writing, drafting of paper and approval of draft.

\section{Funding}

No grants or financial support to be declared.

\section{Provenance and Conflict of interest}

This paper was not commissioned. There are no conflicts of interest to declare.

\section{References}

1. Gerdzt M, Collins M, Chu M, Grant A, Tchernomoroff R, Pollard $C$, et al. Optimizing triage consistency in Australian emergency departments: The Emergency Triage Education Kit. Emerg Med Australas 2008;20:250-9.

2. McCallum Pardy T. The clinical practice of Emergency Department Triage: application of the Australasian Triage Scale - an extended literature review Part 1: evolution of the ATS. Australas Emerg Nurs J 2006; 9:155-62.

3. Triage FM. In: Curtis K, Ramsden C, Friendship J, editors. Emergency \& trauma nursing. Sydney: Mosby Elsevier; 2007. 
4. Forero R, Nugus P. Australasian College for Emergency Medicine (ACEM) Literature review on the Australasian Triage Scale (ATS). ACEM; 2012.

5. ACEM. Guidelines on the implementation of the Australasian Triage Scale in emergency departments. Australasian College for Emergency Medicine; 2000.

6. McCallum Pardy T. Emergency triage. Australas Emerg Nurs J 2007;10:43-5.

7. Department of Health and Ageing. Emergency triage education kit. In: Ageing. Canberra: DOHA; 2007.

8. CASP. 11 questions to help you make sense of a case-control study. England: Public Health Resource Unit, NHS; 2006.

9. Considine J, LeVasseur S, Villanueva E. The Australasian Triage Scale: examining Emergency Department Nurses' performance using computer and paper scenarios. Ann Emerg Med 2004;44(5):516-23.

10. LeVasseur S, Charles A, Considine J, Berry D, Orchard T, Woiwood M, et al. Consistency of triage in Victoria's Emergency Departments: triage consistency report. Victoria, Australia: Monash Institute of Health Services Research; 2001.

11. Le Vasseur S, Charles A, Considine J. Consistency of triage in Victoria's Emergency Departments: education and quality report. Melbourne: Services VDoH; 2001.

12. Creaton A, Liew $D$, Knott J, wright $M$. Interrater reliability of the Australasian Triage Scale for mental health patients. Emerg Med Australas 2008;20:468-74.

13. Considine J, LeVasseur S, Charles A. Development of physiological discriminators for the Australasian Triage Scale. Accid Emerg Nurs 2002;10:221-34.

14. Gerdtz M, Chu M, Collins M, Considine J, Crellin D, Sands N, et al. Factors influencing consistency of triage using the Australasian Triage Scale: implications for guideline development. Emerg Med Australas 2009;21:277-85.

15. Considine J, Ung L, Thomas S. Triage nurses' decisions using the National Triage Scale for Australian emergency departments. Accid Emerg Nurs 2000;8:201-9.

16. Doherty S. Application of the National Triage Scale is not uniform. Aust Emerg Nurs J 1996;1(1):26.

17. Fry M, Burr G. Current triage practice and influences affecting clinical decision-making in emergency departments in NSW. Aust Accid Emerg Nurs 2001;9:227-34.
18. Innes K, Plummer V, Considine J. Nurses' perceptions of their preparation for triage. Australas Emerg Nurs J 2011;14:81-6.

19. Gerdtz M, Bucknall T. Influence of task properties and subjectivity on consistency of triage: a simulation study. J Adv Nurs 2007;58(2):180-90.

20. Dilley S, Standen P. Victorian nurses demonstrate concordance in the application of the National Triage Scale. Emerg Med 1998; 10:12-8.

21. Jelinek G, Little $M$. Inter-rater reliability of the National Triage Scale over 11,500 simulated occasions of triage. Ann Emerg Med 1996;8(4):226-30.

22. Livingston S, Lewis C. Estimating the consistency and accuracy of classifications based on test scores. J Educ Meas 1995;32:179-97.

23. Cohen J. A coefficient of agreement for nominal scales. Educ Psychol Meas 1960;20(1):37-46.

24. Terwee C, Bot S, de Boer M, Windt D, Knol D, Dekker J, et al. Quality criteria were proposed for measurement properties of health status questionnaires. J Epidemiol 2007;60(1): $34-42$.

25. van der Wulp I, van Stel H. Adjusting weighted kappa for severity of mistriage decreases reported reliability of emergency department triage systems: a comparative study. J Clin Epidemiol 2009;62:1196-201.

26. Considine J, LeVasseur S, Villanueva E. The Australasian Triage Scale: examining emergency department nurses' performance using computer and paper scenarios. Ann Emerg Med 2004; 44:516-23.

27. de Vet H, Terwee C, Knol D, Bouter L. When to use agreement versus reliability measures. J Epidemiol 2006;59: 1033-9.

28. Gillespie R. Manufacturing knowledge: a history of the Hawthorne experiments. Cambridge: Cambridge University Press; 1991.

29. NSW Health. In: NSW Department of Health, editor. NSW Health System Performance Indicators. Sydney: NSW Health; 2003.

30. Considine J, Le Vasseur S, Charles A. Consistency of triage in Victoria's Emergency Departments: literature review. Melbourne: Victorian Department of Human Services; 2001.

31. Altman D. Practical statistics for medical research. London: Chapman and Hall; 1991. 